\title{
Dış Ticarette Ürün/Ülke Çeşitliliği ve Firma Performansı: Türkiye Örneğ $\mathbf{i}^{1}$
}

Başak DALGIÇ, Department of Public Finance, Faculty of Economics and Administrative Sciences, Hacettepe University, Turkey; e-mail: basakcakar@hacettepe.edu.tr

Burcu FAZLIOĞLU, Department of International Entrepreneurship, Faculty of Economics and Administrative Sciences, TOBB University of Economics and Technology, Turkey; e-mail: bfazlioglu@etu.edu.tr

\section{Trade Diversification and Firm Performance: The Turkish Case ${ }^{2}$}

\begin{abstract}
We examine the effects of trade diversification in terms of both countries and products on firm performance with a special focus on the differentials between importing and exporting activities. We utilize a rich and recent dataset for Turkish manufacturing firms over the period 2003-2010. Our results suggest that the more diversified are the firms in terms of products and countries the better they perform. Diversication of importing benefit firms more than diversification of exporting. Moreover diversification premia are much higher in terms of country extensive margins with respect to product extensive margins.

Keywords

: Trade Diversification, Extensive Margins, Firm Heterogeneity, Imports, Exports.

JEL Classification Codes : F10, D21, D24, C21, C2.

1 Bu çalışma TÜBİTAK (Türkiye Bilimsel ve Teknik Araştırma Kurumu) tarafindan 113 K378 numarall, Türkiye Imalat Sanayinde Firma Heterojenliği Ve Dış Ticaret"başlıklı proje kapsamında desteklenmiştir. Çalışmanın gerçekleștirilebilmesi için firma düzeyinde veriye ulaşmamızı sağlayan TÜIK (Türkiye İstatistik Kurumu) personeli Doğan Böncü, Şenol Bozdăg, Nusret Kllıç, Nilgün Arıkan, Erdal Yıldırım, Kenan Orhan, Bülent Tungul, Aknn Bodur, Sabit Cengiz Ceylan ve Ferhat Irmak'a da teşekkür ederiz.

2 We acknowledge the generous financial support of TÜBITTAK (The Scientific and Technological Research Council of Turkey) from the budget of the project entitled "Firm Heterogeneity in Turkish Manufacturing Industry and International Trade" with project number 113K378. We thank TURKSTAT (Turkish State Institute of Statistics) and particularly, TURKSTAT staff Doğan Böncü, Şenol Bozdă̆, Nusret Kıllı̧, Nilgün Arıkan, Erdal Yıldırım, Kenan Orhan, Bülent Tungul, Akın Bodur, Sabit Cengiz Ceylan and Ferhat Irmak for providing access to firm level data.
\end{abstract}




\section{$\ddot{\mathbf{O} z}$}

$\mathrm{Bu}$ çalışmada uluslararası ticaretteki ürün ve ülke çeşitlenmesinin firma performansı üzerindeki etkileri, ihracat ve ithalatın getirilerindeki farklılıklara da odaklanılarak analiz edilmektedir. Türkiye imalat sanayi firmaları için 2003-2010 dönemine ait zengin ve güncel bir veri seti kullanılmaktadır. Çalışmadan elde edilen sonuçlara göre firmalar ürün/ülke çeșitlenmesi bakımından ne kadar gelişmişlerse o kadar iyi performans göstermektedirler. İthalattaki çeşitlenme firmalara ihracattaki çeşitlenmeye göre daha fazla yarar sağlamaktadır. Bununla birlikte dış ticaretteki ülke çeşitlenmesinin ortaya çıkardığı performans primleri ürün çeşitlemesine göre daha yüksektir.

Anahtar Sözcükler $\quad$ : Uluslararası Ticarette Ürün ve Pazar Çeşitlenmesi, Firma Heterojenliği, İthalat, İhracat.

\section{Giriș ve Literatür İncelemesi}

Firma heterojenliğine ilişkin yazının bir bölümü, firmaların dış ticarette çeşitlenmesini etkileyen faktörlere; başka bir deyişle firma performansı-dış ticarette çeşitlenme bağlantısı üzerine gelişmektedir. Söz konusu yazın, özellikle çok ürünlü firmalara ve bu firmaların birden fazla dış ticaret pazarında varoluşları üzerine yoğunlaşmaktadır. Örneğin, Bernard vd. (2010), çalışmalarının teorik temellerini Melitz'in (2003) çalışmasına bina etmiş ve heterojen firmaların çok sayıda ürünü birden çok sayıda pazara ihraç ettiği bir genel denge çerçevesi geliştirmiş̧lerdir. Bernard vd. batık maliyetler ürüne ve pazara özgü olduğundan yalnızca en üretken firmaların geniş bir ürün yelpazesini çok sayıda pazara satabileceğini gösterirler. Ampirik açıdan bu mesele, ihracat çeşitliliğini hedef pazarların özellikleri ile ilişkilendirecek şekilde çekim modelleri (gravity models) çerçevesinde ele alınmaktadır. (Bernard vd., 2007; Parteka \& Tambieri, 2011; Arkolakis \& Muendler; 2012; Cadot vd. 2011). Öte yandan diş ticarette çeşitlenmenin kapsamlı bir analizi, bu sürecin dış ticareti gerçekleştiren firmalar düzeyinde ele alınmasını gerektirmektedir. Çeşitlenmenin firma performansı üzerindeki etkisini firma düzeyinde ampirik olarak ele alan az sayıda çalışma bulunmaktadır. İlgili çalışmaların çoğu özellikle gelişmiş ülkelere odaklanmış olup yalnızca firmaların ihracat faaliyetleri üzerinde durmaktadırlar (Muuls \& Pisu, 2009; Castellani vd., 2010).

$\mathrm{Bu}$ çalışma, firmaların hem ihracat hem de ithalat faaliyetlerini göz önünde bulundurarak; dış ticaretteki ürün ve pazar çeşitlenmesinin firma performansı üzerindeki etkilerine odaklanmakta ve çeşitlenme sürecinin anlaşılmasına katkıda bulunmaktadır. Çalışma 2003-2010 döneminde, 19+ çalışanı olan tüm Türkiye imalat sanayi firmalarını ${ }^{3}$

3 Ilgili dönemde Türkiye imalat sanayinin GSYIH'daki ortalama payı yüzde 23.5'di ve imalat sanayi Türkiye'deki genel istihdamin yüzde 13.5 'ini olușturmasına rağmen toplam ihracat hacminin yüzde 93.5 'ini oluşturmaktaydl. 
kapsamaktadır. Çalışmamız öncelikle, dış ticaretin büyümenin lokomotiflerinden biri olduğu gelişmekte olan bir ekonomiyi ele alması açısından ${ }^{4}$ önem arz etmektedir. Bununla birlikte ele aldığımız dönem, Türkiye'nin dış ticarette önemli gelişmeler kaydettiği ${ }^{5}$, sektörel ve coğrafî çeşitlenmenin yanı sıra ekonominin de yapısal bir dönüşüm geçirdiği bir zaman dilimini kapsamaktadır. Türkiye bu dönemde, tekstil ve giyim odaklı geleneksel ihracat sektörlerinden makine ve metal sanayine doğru bir yapısal değişime tanıklık etmiştir. Aynı dönemde Avrupa Birliği (AB) ve Avrupa Serbest Ticaret birliği (EFTA) ülkelerinden Orta Doğu ve Kuzey Afrika'daki (MENA) yeni pazarlara geçişler olmuştur.

Michaely'nin (1958) çalışmasına kadar geriye uzanan bir yazın, dış ticarette ürün ve pazar çeşitlenmesi ile ilgilenmiştir. Imbs ve Wacziarg'ın (2003) üretimde çeşitlenme ve yoğunlaşmayı incelediği çalışması, uluslararası ticaretle ilgilenen araştırmacılara, çalışmanın bulgularının dış ticaret için doğruluğunu araştırmak için yeni fikirler vermiştir. İlgili yazındaki dönüm noktası ise, Melitz (2003) ve Bernard vd.'nin (2003) dış ticaret modellerinde firma heterojenliğine yer veren çığır açıcı çalışmalarıdır. Bu yazın, özellikle çok ürünlü firmalara ve bu firmaların çok sayıda dış ticaret pazarında varoluşları üzerine yoğunlaşır. Buna göre, ürüne ve pazara özgü batık maliyetlerin varlığından dolayı yalnızca en üretken firmalar çok sayıda ürünü çok sayıda pazara satabilmektedir. Mayer vd. (2011), hedef pazardaki rekabetin firmanın ihraç ettiği ürün çeşitliliği ve ürün karışımı üzerindeki rolünü vurgulayan bir çok-ürünlü-firma modeli oluşturmuşlardır. Söz konusu çalışma, ihracat pazarlarındaki yüksek rekabetin firmaları, en iyi performans gösterdikleri ürünler üzerinde yoğunlaşmaya ittiğini göstermektedir.

Teorik yazının yanı sıra ampirik literatür de firmaların pazar ve ürün çeşitlenmesini (ülke ve ürün ekstansif marjinleri) incelemektedir (bkz. Mayer \& Ottoviano, 2007). Bu doğrultuda, birçok çalışmada verimlilik ile pazar ve ürün çeşitliliği arasında

Bu rakam daha sonra toplam ihracatın yüzde 80 ’ine kadar düştüyse de Türkiye bu payla, imalat sektörünün ihracat içindeki payı açısından BRIC ülkeleri içinde Çin'den sonra ikinci sırada yer almaktadır. Dolayısıyla, imalat sanayi, bu kadar büyük bir pay ile Türkiye'nin ihracat performansının belirlenmesine önemli bir rol oynamaktadır.

4 Türkiye, GSMH'si ile Dünya'da 16. ve Avrupa'da 6. strada yer alan bir üst-orta-gelir ülkesi olup son on yllda, ortalama yüzde 5'lik bir hiz ile büyümüştür. Türkiye’nin GSYIH seviyesi, 2002'deki 231 milyar dolardan 2012'de 786 milyar dolar seviyesine yükselmiş; kişi başl gelir seviyesi ise 2002'deki 3,500 dolardan 2012 'de 10,504 dolar seviyesine çıkarak üç katından fazla artmıştır. Bununla birlikte ele alınan dönem boyunca dış ticaret hacmi GSYIH'nin ortalama yüzde 49.5'ini oluşturmuştur.

5 Türkiye'nin toplam ticaret hacmi, 2002'deki 88 milyar dolarllk seviyesinden 2012'de 389 milyar dolar seviyesine yükselmiştir ve bu artış, sadece on yılda yüzde 342 'lik bir artışı teşkil etmektedir. Türkiye'nin ihracatı, aynı dönem içinde yüzde 325 artmıştır (36 milyardan 153 milyara). Bu rakam, aynı dönemde toplam ihracatları ortalama yüzde 212 büyüyen aynı gelir grubundaki ülkelerin (Brezilya, Çin, Meksika ve Güney Afrika) ihracat performanslarina benzemektedir. 
pozitif bir ilişki olduğu bulunmuştur. Söz konusu çalışmalarda, diş ticaretin hem ürün bazında hem de coğrafi olarak çeşitlenmesi yüksek olan bir sektördeki sınırlı sayıda firmanın elinde yoğunlaştığı gözlemlenmiştir. Ticaretin çok sayıda ürünü çok sayıda pazara satan az sayıda firma tarafından gerçekleştirilmesinin nedeni, ihracatçıların ek maliyetlere maruz kaldığına ilişkin teorik görüş ile ilişkilendirilebilir. Bernard vd.'nin (2007) ABD, Muuls ve Pisu'nun (2007) Belçika, Eaton vd.'nin (2004) Fransa ve Castellani vd.'nin (2010) İtalya için yaptığı çalışmalar, bu teorik çerçeveyi destekler niteliktedir.

$\mathrm{Bu}$ çalışmada uluslararası ticaret ve firma heterojenliğine ilişkin literatüre şu açılardan katkıda bulunmaktayız: Öncelikle, bilgimizin sınırları dâhilinde çalışmamız Türkiye için dış ticarette çeşitlenme-firma performansı ilişkisini araştıran ilk çalışmadır. Bununla birlikte, özellikle az gelişmiş ülkeler için, firmaların ihracat ve ithalât faaliyetlerine ilişkin marjlarını aynı anda analiz eden çalışma sayısı oldukça sınırlıdır. Bu çalışma, Türkiye örneği ile gelişmekte olan ülkelere ilişkin yazına katkıda bulunmaktadır. Son olarak, analiz yöntemimiz ihracat ve ithalâttaki çeşitlenmenin firma performansı üzerindeki etkilerinin karşılaştırılmasına da olanak sağlamaktadır.

Çalışmamızın sonuçlarına göre, firmalar ürün ve pazar çeşitliliği bakımından ne kadar gelişmişse, o kadar büyük, sermaye yoğun ve üretken olmaktadır. İthalatta ortaya çıkan ülke/ürün çeşitlenmesi firma performansına, ihracat çeşitlenmesine göre daha büyük katkılar sağlamaktadır. Diğer taraftan, ürünlerin teknolojik içeriği ve karmaşıklığından bağımsız olarak daha çeşitli firmaların daha üretken olduğu gözlemlenmektedir. Son olarak, ülke/ürün çeşitlenmesinin getirileri sermaye malı ihraç/ithal eden firmalar için tüketim malı ihraç/ithal eden firmalara göre daha yüksektir.

Çalışmanın kalan kısmı şu bölümlerden oluşmaktadır: İkinci kısım ampirik analizlerde kullanılan verileri tanıtmakta; firmaların dış ticaret dinamikleri ve dış ticarete ilişkin ürün/ülke çeşitlenmesi olarak tanımladığımız ekstansif marjinlerle ilgili tanımlayıcı istatistikler sunmaktadır. Üçüncü kısım ampirik analizlerimize ilişkin bulguları ortaya koymaktadır. Çalışma sonuç bölümüyle tamamlanmaktadır.

\section{Veriler ve Ön Bulgular}

Bu çalışma, Türkiye İstatistik Kurumu (TÜİK) tarafından toplanan iki farklı veri kaynağının birleştirilmesiyle oluşturulmuş bir veri setine dayanmaktadır. Bunlardan ilki Yıllık Sanayi ve Hizmet İstatistikleri (YSHİ) ikincisi ise Yıllık Dış Ticaret İstatistikleri (YTİ)'dir. YSHİ, 19'dan fazla çalışanı olan firmalar için bir tam sayım iken 20'den az çalışanı olan firmalar için temsil edici bir örneklemdir. Çalışmada, 20 veya daha fazla 
çalışanı ${ }^{6}$ olan Türkiye imalat sanayi firmalarının tümü ele alınmıştır. YSHİ veri setinde firmalar, EUROSTAT'ın NACE Rev.1.1 ana faaliyet kodlarına göre sınıflandırılmışlardır. Veri seti, gelirler, katma değer, işçilik maliyeti ve ara girdi maliyetleri gibi bir firmanın bilânçosunda görünen çeşitli yapısal değişkenlerin yanı sıra firmanın coğrafi konumu, yabancı sermaye dağılımı ve çalışan sayısına ilişkin bilgiler de sağlamaktadır. Firmaların sermaye stoku serileri sürekli envanter yöntemi (perpetual inventory methodology) kullanılarak tarafımızca hesaplanmaktadır.

İkinci veri kaynağı olan YTİ, gümrük bildirimlerine dayanmaktadır. İthalât ve ihracat akımları, 12 basamaklı Gümrük Tarife İstatistik Pozisyonu (GTIP) sınıflandırmasındaki tüm ithalât ve ihracatı kapsamaktadır. Veri setinde ayrıca ticaret akımlarının menşe/pazar ülkelerine ilişkin bilgiler de mevcuttur. Bahsi geçen iki veri setinin birleştirilmesiyle oluşturulmuş dengelenmemiş panelimiz, 2003-2010 yılları arasında toplam 38.223 firmaya ait bilgileri içermektedir. Orijinal veri setindeki firma sayısı daha fazla olup, veriye büyük ölçüde Hall ve Mairesse'den (1995) esinlenen bir temizleme prosedürü uygulanmıştır.

Çalışmada, firma performansına ilişkin temel değişkenlerimiz toplam faktör verimliliği (Total Factor Productivity-TFP) ve işgücü verimliliğidir (Labor ProductivityLP). TFP, Levinsohn ve Petrin'in (2003) metodolojisi kullanılarak tarafimızca hesaplanmaktadır. Levinsohn ve Petrin'in (2003) yarı parametrik yaklaşımı, firmaların ara girdi kullanımını verimlilik şokları için temsili bir değişken olarak kullanılmakta ve TFP'yi Cobb-Douglas teknolojisi altında işgücü ve sermayenin artık değeri olarak hesaplamaktadır. LP ise, çalışan başına katma değer olarak tanımlanan standart işgücü verimliliğidir. Firma ölçeğini veya büyüklüğünü ölçmek için, toplam satışlar (SALES) ve çalışan sayıs1 (EMPLOYEE) kullanılmaktadır. Firmanın sermaye yoğunluğu (CAPINT), sermaye stoğunun çalışan sayısına oranı olarak tanımlanır. Beceri yoğunluğunu tayin etmek için çalışan kişi başına düşen ücret kullanılmaktadır (WAGE_L).

Bu çalışmada temel olarak ürün/ülke ektansif marjinleri kapsamında dış ticaretin çeşitlenmesini araştırmaktayız. Ürün ektansif marjinleri (NPE / NPI), bir firmanın ihraç/ithal ettiği ürün sayısını tanımlamaktadır". Her bir "ürün" ise 6 basamaklı bir Harmonize Sistem (HS) ürün kategorisine tekabül etmektedir. Ülke ektansif marjinleri ise (NCE / NCI), bir

20 ve daha fazla çalışanı olan firmalar, Türkiye imalat sanayinin büyük bir bölümünü oluşturmaktadır. Örneğin, bu firmalar 2009 yllinda toplam üretimin yüzde 87 'sini ve istihdamin ise yüzde 75 'ini oluşturmuşlardır. Diğer yıllarda da benzer bir durum görülmektedir. Bununla birlikte, batık maliyetlerin varlığında ticaret faaliyeti genelde büyük firmalar tarafindan gerçekleştirildiğinden, seçimimiz yanlı sonuçlar yaratmamaktadır.

7 İhraç edilen ürün sayısı NPE, ithal edilen ürün sayısı NPI olarak etiketlenmiştir. 
firmanın ihracat/ithalât yaptığı ülke sayısını tanımlamaktadır ${ }^{8}$. Türkiye imalât sanayi firmaları analiz dönemi boyunca ortalama olarak 10 ürünü 7 ülkeye ihraç ederken; 17 ürünü 6 ülkeden ithal etmiştir ${ }^{9}$. Bu rakamlar, gelişmiş ülkelere ilişkin örneklere göre küçüktür (bkz. Muuls \& Pisu, 2009; Bernard vd., 2009). Şekil 1'de, ürün/ülke ektansif marjinlerinin yıllar içerisindeki değişimi sunulmaktadır. Şekil 1'den görüldüğü üzere Türkiye imalât sanayi 2003 ve $2009^{10}$ yılları arasında, hem ithalâtta hem de ihracatta ürün ve ülke çeşitliliğini arttırmıştır. Bahsi geçen çeşitlilik artışının, ithalât için ihracata göre daha az olduğu görülmektedir.

\section{İhracat ve İthalatta Ürün/ Ülke Ekstansif Marjinleri (2003-2010)}

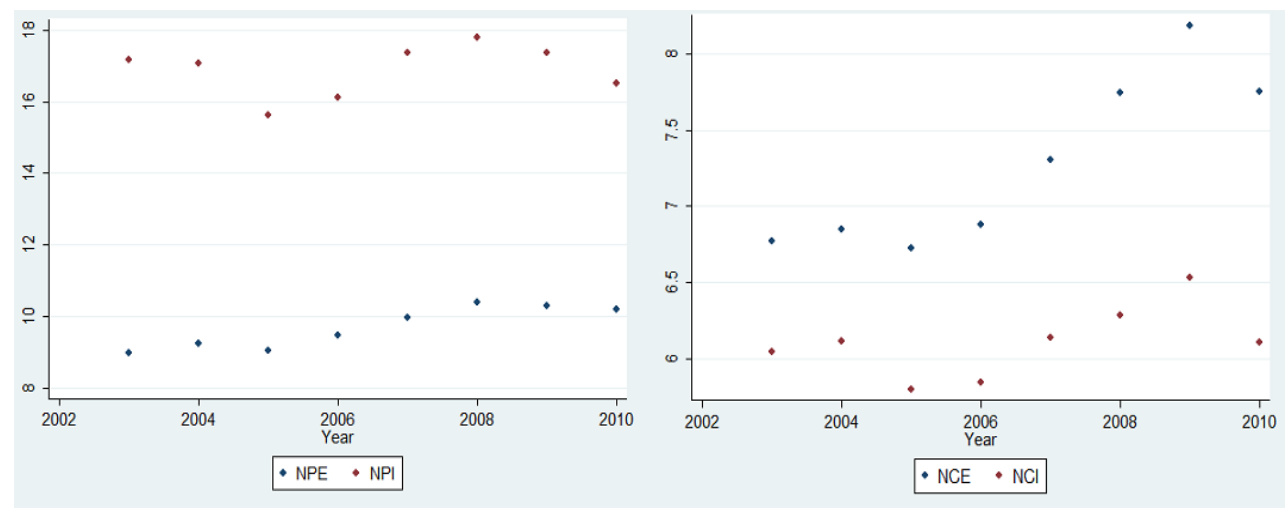

Tablo 1'de, 2003 ve 2009 yılları arasında firmalar, ihraç ettikleri ürün ve ülke sayısına göre gruplara (çeşitlilik aralıklarına) ayrılmakta ve belirlenen gruplar arasındaki geçişler gösterilmektedir ${ }^{11}$. Endüstriye giriş/çıkışların en fazla yaşandığı grup, 1-5 ülkeye ihracat yapan firmaların oluşturduğu gruptur. En durağan grup ise $21+$ ülkeye ihracat yapan firmalar grubudur. Benzer bir yapı, ihraç edilen ürünlerin sayısı açısından da mevcuttur. En yüksek giriş ve çıkış oranı, 1-5 ürünü ihraç eden firmalarda meydana gelirken, giriş çıkışların

8 Ihracat yapılan ülke sayısı NCE, ithalat yapılan ülke sayısı NCI olarak etiketlenmiştir.

9 Veri setimizde maksimum 423 farklı çeşit ihracat ürünü (HS6), ihracat yapılan maksimum 110 farkl farklı çeşit ithalat ürünü (HS6) ve ithalat yapılan maksimum 64 farklı ülke mevcuttur.

10 Kriz etkisi dolayısıla, 2010 yılı bu büyüme hesaplamalarına dâhil edilmemektedir.

11 Makaleyi kısa ve öz tutmak adına aynı tablolar ithalât için sunulmamaktadır. Ancak, bu tablolar yazarlardan istek üzerine temin edilebilir. 
en az yaşandığı firma grubu 21 ve daha fazla ürünü ihraç eden firmalardır. Ayrıca, çeşitlenme bakımından üst aralıklara çıktıkça, üst ürün/ülke aralığına doğru hareket eden firma yüzdesinin azaldığ Tablo 1'den gözlemlenebilir.

Tablo: 1

Ürün ve Ülke Bazındaki Marjların Aralıklarında Geçiş Yapan Firmalar, İhracatlar (2003-2010)

\begin{tabular}{|c|c|c|c|c|c|c|c|c|}
\hline \multicolumn{9}{|c|}{ NPE } \\
\hline & 2003 & $1-5$ & $6-10$ & $11--20$ & $21+$ & Çıkış & Giriş & 2010 \\
\hline $1-5$ & 3955 & 1231 & 234 & 102 & 46 & 2010 & 2227 & 5850 \\
\hline $6-10$ & 1227 & 394 & 174 & 102 & 39 & 545 & 607 & 1861 \\
\hline $11-20$ & 944 & 207 & 180 & 196 & 68 & 373 & 459 & 1483 \\
\hline $21+$ & 680 & 113 & 94 & 171 & 266 & 261 & 376 & 1281 \\
\hline Total & 6806 & 1945 & 682 & 571 & 419 & 3189 & 3669 & 10475 \\
\hline \multicolumn{9}{|l|}{ NCE } \\
\hline & 2003 & $1-5$ & $6-10$ & $11--20$ & $21+$ & Çıkış & Giriş & 2010 \\
\hline $1-5$ & 4273 & 1184 & 210 & 82 & 20 & 2353 & 2439 & 6288 \\
\hline $6-10$ & 1205 & 423 & 227 & 94 & 12 & 462 & 642 & 1860 \\
\hline $11-20$ & 889 & 237 & 221 & 204 & 41 & 281 & 377 & 1361 \\
\hline $21+$ & 439 & 76 & 85 & 228 & 273 & 93 & 211 & 966 \\
\hline Total & 6806 & 1920 & 743 & 608 & 346 & 3189 & 3669 & 10475 \\
\hline
\end{tabular}

Güncel yazın, dış ticarette yoğunlaşmanın sadece firmalar arasında değil, ürün/ülke ekstansif marjinlerinde de gözlemlendiğini göstermiştir. İlgili literatür, ihracatçı firmaların çoğunluğunun az sayıda ülkeye ya da az sayıda piyasaya satış yaptığını, dolayısıyla her firmanın ticaret yaptığı ülke sayısı ile bu ülkelere satış yapan firma sayısı arasında negatif ilişkinin varlığını göstermişlerdir (benzer bulgular için bkz. Damijan vd. 2004; Muuls \& Pisu, 2007; Andersson vd., 2008). Yazında kabul gören bu olgu sadece en iyi performans gösteren firmaların alım-satım faaliyetlerini çeşitlendirebileceğine ilişkin teorik görüş ile tutarlıdır.

Yazında kabul gören bu olgular, Türkiye imalat sanayi örneği için de doğrulanmaktadır. Şekil 2'de, ithalatçıların ve ihracatçıların ürün/ülke ekstansif marjinleri ve her bir marjine düşen firmaların yüzdesi verilmiştir. Görüleceği üzere, ihracat/ithalat yapan firma sayısı monoton bir şekilde düşmektedir. Ortalama ithal/ihraç edilmiş ürünlerin sayısına bakıldığında da benzer bir tablo ortaya çıkmaktadır. Bununla birlikte NCI [0; 56] aralığında değişirken NCE [0; 107] aralığında değişmektedir. Ürün marjinlerine bakıldığında ise durum tam tersidir. NPE'nin desteği NPI'nın desteğine göre daha azdır. NPE [0; 402] aralığında iken NPI [0; 1054] aralı̆̆ındadır. 
Şekil: 2

Sektör (Ülke) Bazında Marjdaki İthalatçıların (İhracatçıların) Sayısı (2003)
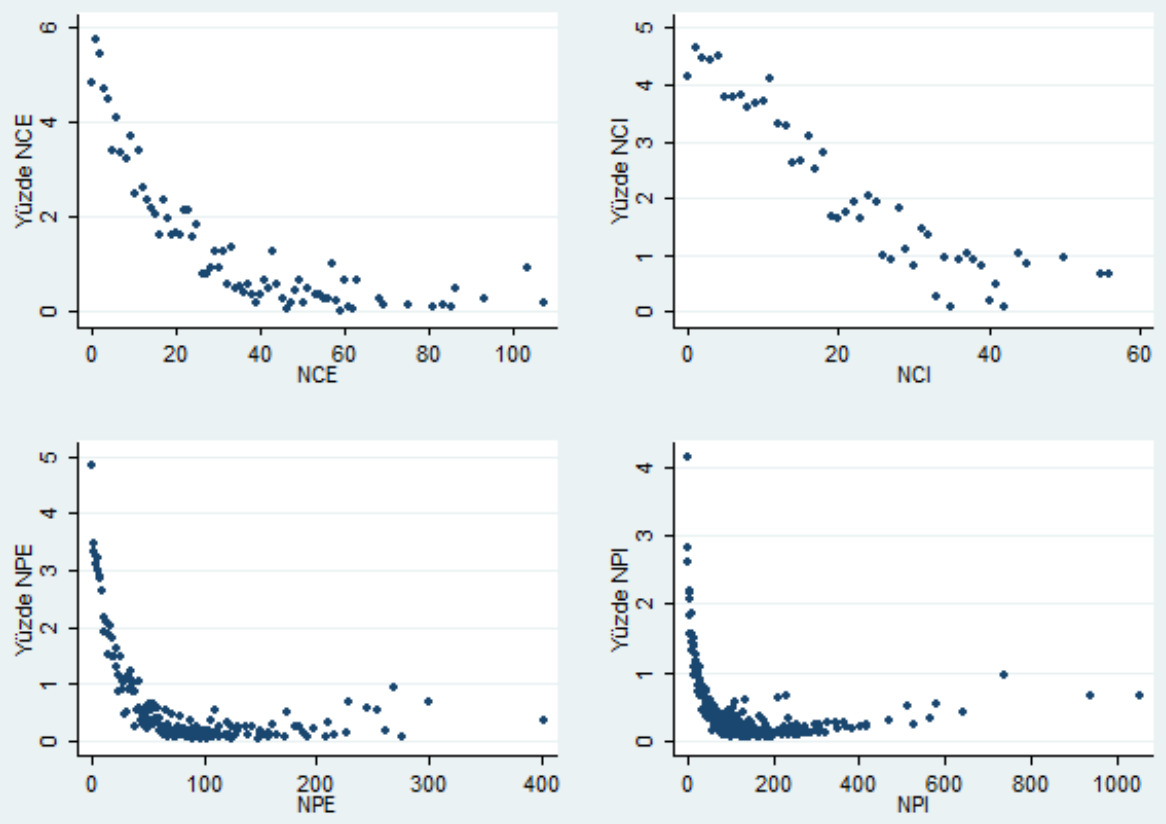

$\mathrm{Bu}$ analizi takiben, dış ticarette ürün ve ülke çeşitlenmesinin firma performansı üzerindeki etkisini ve söz konusu etkinin ithalât ile ihracat için nasıl farklılaşacağının araştııılması amacıyla çalışmanın bir sonraki aşamasında çift taraflı ticaret yapan firmalara yoğunlaşmaktayız. Analiz dönemi boyunca, tüm firmaların yaklaşık yüzde 64'ü dış ticaret yapmakta olup, çift taraflı ticaret yapan firmalar \%39 ile dış ticaret yapan firmalar içerisinde en büyük payı oluşturmaktadırlar. Diğer taraftan, sadece ithalat veya sadece ihracatla uğraşan firmalar azınlıktadır (sadece ihracat yapanların payı \%11 ve sadece ithalat yapanlarınki ise \%13'dür).

$\mathrm{Bu}$ aşamada öncelikle, çift taraflı dış ticaret yapan firmaları ürün/ülke ekstansif marjinlerine göre gruplandırmakta ve ilgili grupların ortalama üretkenliklerinin nasıl farklılaştığını incelemekteyiz. Tablo 2'deki ilk grup 6'dan az mal (ülke) ile dış ticaret yapan firmalardan oluşurken, ikinci grup 6-10 mal (ülke) ile dış ticaret yapan firmaları, üçüncü grup 11-20 mal (ülke) ile dış ticaret yapan firmaları ve son grup 20'den fazla mal (ülke) ile 
dış ticaret yapan firmaları kapsamaktadır. Tablo 2, dış ticarette ürün ve ülke çeşitlenmesi arttıkça üretkenlik düzeyinin de arttığını göstermektedir. Örneğin, 10 üründen fazla ürün ihraç eden firmaların TFP'si, 6'dan az ürün ihraç eden firmalarınkine göre ortalama yüzde 8 oranında daha yüksektir. Ayrıca, söz konusu farkın ithalâtta ihracata göre daha belirgin olduğu gözlemlenmektedir.

Tablo 2 aynı zamanda, dış ticaret yapılan ürün veya ülke sayısının düşük olması durumunda (örneğin 1-5), ihracatçı firmaların verimliliğinin ithalâtçı firmalarınkinden daha yüksek olduğunu göstermektedir. Ürün veya ülke sayısı arttıkça, bu durum tersine dönmekte ve ithalâtçı firmaların verimlilikleri ihracatçılarınkini geçmektedir. Söz konusu gözlem, Türkiye için ithal edilen ürün veya ithalât yapılan ülke sayısı arttıkça sabit maliyetlerin arttığına dair hipotez ile ilişkili olabilir. Bununla birlikte söz konusu hipotez, Türkiye; genel olarak daha açık ve kolay erişimli AB piyasalarına ihracat yaptığından ihracat tarafında daha az geçerli olabilir. Detaylıca incelendiğinde, AB Türkiye'nin ana ithalât ortağı olmasına rağmen Çin ve ABD gibi uzak ülkelerin de Türkiye'nin toplam ithalâtında göz ardı edilemez payları olduğu görülmektedir ${ }^{12}$. Buna ek olarak, tüketim malı ithalâtına göre daha yüksek batık maliyetler içeren yatırım ve ara malları ithalâtı toplam ithalâtın büyük bir parçasını oluşturmaktadır ${ }^{13}$.

Tablo: 2

Çift Taraflı Dış Ticaret Yapan Firmaların Ektansif Marjinlere Göre Verimliliği (2003-2010)

\begin{tabular}{l|llllllll}
\hline & NPE & & NPI & & NCE & & NCI & \\
\hline & $T F P$ & $L P$ & $T F P$ & $L P$ & $T F P$ & $L P$ & $T F P$ & $L P$ \\
\hline \hline $\mathbf{1 - 5}$ & 7.62 & 10.04 & 7.55 & 9.97 & 7.68 & 10.05 & 7.59 & 10.02 \\
$\mathbf{6 - 1 0}$ & 7.75 & 10.21 & 7.85 & 10.23 & 7.84 & 10.24 & 8.08 & 10.43 \\
$\mathbf{1 1 - 2 0}$ & 7.96 & 10.29 & 8.06 & 10.37 & 7.84 & 10.42 & 8.28 & 10.68 \\
$\mathbf{2 0 +}$ & 8.23 & 10.48 & 8.25 & 10.74 & 8.09 & 10.7 & 8.52 & 11.07 \\
\hline \hline
\end{tabular}

122013 yılında Türkiye 'nin ilk beş sıradaki ihracat ortağı Almanya, Irak, Birleşik Krallık, İtalya ve Fransa iken Rusya, Çin, Almanya, ABD ve Italya Türkiye'nin toplam ithalatında en büyük paya sahip olan ticaret ortaklarıdır (Ekonomi Bakanlı̆̆l-Ekonomik Görünüm Raporu, 2014).

132013 yılında yatırım ve ara mallarının Türkiye'nin toplam ihracatındaki payı yaklaşık yüzde 60 iken bu pay ithalâtta yüzde 88 olarak gerçekleşmiştir (Ekonomi Bakanlı̆̆ı-Ekonomik Görünüm Raporu, 2014). 


\section{Ampirik Bulgular}

Dış ticarette çeşitliliğinin firma performansına etkisinin ölçülmesinde, firma performansı ile ilişkilendirilebilecek diğer faktörlerin (örneğin sektörel ve diğer firma özellikleri) kontrol edilmesi gerekir. Bu nedenle çalışmanın bu aşamasında aşağıda belirtilen model belirtimi tahmin edilmektedir:

$$
y_{i t}=\alpha+\beta^{1} x_{i t}^{N P E}+\beta^{2} x_{i t}^{N P I}+\beta^{3} x_{i t}^{N C E}+\beta^{4} x_{i t}^{N C I}+\delta \text { Controls }+\varepsilon_{i t}
$$

Burada bağımlı değişken olan $y_{i t}$ firma performansını ifade etmekte olup ve firmanın satışları, çalışan sayısın işgücü verimliliği, toplam faktör verimliliği, sermaye yoğunluğu ve çalışan başına düşen ücretin logaritmik değeri ile ölçülmektedir. ${ }^{x_{i t}}$ değişkeni ürün/ülke ekstansif marjinlerini belirtir (sırasıyla NPE, NPI, NCE, NCI). Kontroller vektörü ise sırasıyla firmanın çalışan sayısını, iki basamaklı sektör kukla değişkenlerini, bölge ${ }^{14}$ ve yıl kukla değişkenlerini içerir. Çalışmada, yabancı sermayenin varlığını belirten bir yabancı sermaye kukla değişkeni de kontrol değişkeni olarak modele dâhil edilmektedir. Her bir regresyon, analiz dönemi boyunca çift taraflı diş ticaret yapan firmalar için yapılmaktadır. Bu seçim, NCE, NPE, NCI ve NPI'nın sıfır olmayan değerlere sahip olmasını sağlamak, bunları logaritma ile ifade etmek ve hesaplanan $\beta$ katsayılarını esneklikler olarak yorumlamak için gereklidir. Denklem (1)'deki ürün/ülke marjinlerine ilişkin değişkenlerin önündeki $\beta_{1}, \beta_{2}, \beta_{3}$ ve $\beta_{4}$ katsayıları, performans göstergelerinin çeşitlenmeye göre esnekliklerini vermektedir. Örneğin, $\beta_{3}$ ihracat pazarı sayısındaki yüzde 1’lik bir artışın firma performansı üzerinde yarattığı yüzde değişimi göstermektedir.

Sıradan en küçük kareler (OLS), sabit etkiler (FE) ve genelleştirilmiş momentler yöntemi (GMM) ile yapılan regresyon sonuçları Tablo 3'te gösterilmiştir. Firma performansına ilişkin her bir gösterge için ilk sütunda standart OLS regresyonunun sonuçları verilmektedir; ikinci sütunda, firma heterojenliğine ilişkin gözlemlenemeyen faktörleri kontrol etmek üzere kullanılan sabit etkiler modeli regresyon sonuçları yer almakta son sütunda ise dinamik model belirtiminin sonuçları yer almaktadır.

Tablo 3’teki OLS sonuçları, firma büyüklüğü, sektör, yabancı sermaye, bölge ve zaman faktörleri kontrol edildiğinde dahi ürün/pazar çeşitlenmesi yüksek olan firmaların daha büyük, daha üretken ve daha sermaye yoğun olduğunu göstermektedir. Bununla birlikte ithalat çeşitlenmesi ile firma heterojenliği arasında ihracata göre daha güçlü bir ilişki

\footnotetext{
14 Bölge kukla değişkenleri, NUTS2 sınıflandırmasına göre dă̆llmış 12 bölgeyi tanımlar.
} 
olduğunu da belirtmek gerekir. Başka bir deyişle ithalattaki ürün/pazar çeşitlenmesi ihracata göre daha yüksek çeşitlenme primi yaratır. Örneğin ithalat yapılan ülke sayısındaki (NCI) yüzde 1'lik bir artış, işgücü verimliliğinde yüzde 0.18 'lik bir artışa yol açarken, ihracat pazarları sayısındaki (NCE) yüzde 1'lik bir artış, işgücü verimliliğinde yüzde 0.04'lik bir artış ile ilişkilendirilir. Tablo 3'den ayrıca ülke çeşitliliğinin ürün çeşitliliğine göre daha yüksek performans artışına neden olduğu sonucu da çıkarılabilir. Bu bulgu, yeni bir dış ticaret pazarına girmenin yeni bir ürün ihraç etmekten daha yüksek batık maliyetler içerdiğine işaret etmektedir.

Denklem (1) firmalara özgü ve zaman içerisinde değişmeyen sabit etkilerin modele dâhil edilmesiyle de tahmin edilmiştir. Firma karakteristiklerinin diş ticaret yapma durumu ile son derece ilişkili olduğu göz önünde bulundurulduğunda, çeşitlenmenin firma performansına etkisini tespit etmek için tahmin edilecek bir modele firmalara özgü sabit etkilerin dahil edilmesi oldukça önemlidir. Dolayısıyla, firmalara özgü özellikler dış ticaret yapma durumu ile ilişkiliyse, iki model belirtiminin (OLS ve FE) katsayıları arasında farklılıklar olması beklenen bir sonuçtur. Firma heterojenliğine ilişkin gözlemlenemeyen faktörlerin kontrol edilmesi katsayıların değerini büyük oranda düşürse de ülke/ürün çeşitlenmesinin firma performansı üzerindeki etkisi halen gözlemlenebilmektedir. Örneğin TFP'ye bakıldığında, ithal edilen ürünlerin sayısındaki (NPI) yüzde 1'lik bir artış, OLS tahmininde yaklaşık yüzde 0.13 'lük bir artış ile ilişkilendirilirken FE modelinde bu değer yüzde 0.04 'e düşmektedir. Ayrıca, firmalara özgü faktörler göz önünde bulundurulduğunda, ithalata ilişkin katsayıda ihracata göre daha küçük bir düşüş görülmektedir. Örneğin TFP için, NCE'ye ilişkin çeşitlenme primi 0.143 'den 0.05 'e düşerken NCI'ye ilişkin değer daha az düşer $-0.167^{\prime}$ den 0.07 'ye.

Buraya kadar yapılan analizlerin, yalnızca firma performansı ve dış ticaret yapma arasındaki korelasyona dikkat çektiğine ancak herhangi bir nedensellik göstermediğine dikkat edilmelidir. Mevcut yazın ise içselliğin (endogeneity) yaratacağı olası problemleri çözmek için dinamik spesifikasyonlar kullanma konusunda yetersizdir. Dolayısıyla, OLS ve FE regresyonlarındaki olası içsellik problemini ortadan kaldırmak için bir sağlamlık (robustness) analizi olarak da işlev görecek dinamik bir spesifikasyon da kullanmaktayız. $\mathrm{Bu}$ nedenle, gecikmeli bağımlı değişkenin ek bir açıklayıcı değişken olarak modele dahil edildiği bir dizi regresyon yapmaktayız. Gecikmeli bağımlı değişkenin açıklayıcı değişken olarak kullanılması, bu değişkenin birimlere (firmalara) özgü etkiler ile ilişkili olması nedeniyle yanlı ve tutarsız parametre tahminleri üretebilir. Böyle durumlarda, içselliği kontrol etmek için kullanılacak uygun bir yöntem GMM metodolojisidir (Blundell ve Bond 1998; Bond 2002). Bizim örneğimizdeki gibi geniş örneklemlerde ise dinamik modelin standart OLS tahminleri yukarıya doğru yanlı iken grup-içi tahmin edicisi aşağı doğru yanlıdır (Bond 2002; Bernard \& Jensen 2004). Bu doğrultuda, Arellano ve Bond (1991) tarafından önerilen fark GMM prosedürünü kullanmak daha doğrudur. Tablo 3'de GMM tahminlerinden elde edilen sonuçlar sunulmaktadır. Buna göre sonuçlarımız, ürün/pazar 
çeşitlenmesinin firma performansı üzerindeki etkisinin ihracatta ithalata göre daha belirgin olduğunu gösteren önceki bulgularımızla tutarlıdır. Ayrıca, bu regresyonlardaki gecikmeli bağımlı değişkenlerin anlamlı katsayısı, firmanın performansına ilişkin geçmiş değerlerin mevcut durumu etkilediğini doğrulamaktadır.

Tablo: 3

Ürün/Ülke Çeşitlenmesi ve Firma Performansı (2003-2010)

\begin{tabular}{|c|c|c|c|c|c|c|}
\hline & \multicolumn{3}{|c|}{ SALES } & \multicolumn{3}{|c|}{$E M P$} \\
\hline & OLS & $\mathrm{FE}$ & GMM & OLS & $\mathrm{FE}$ & GMM \\
\hline \multirow[t]{2}{*}{$N P E$} & $0.0562 * * *$ & $0.0262 * * *$ & $0.0281 * * *$ & $0.0667 * * *$ & $0.00816^{* *}$ & $0.00691 * * *$ \\
\hline & $(0.00475)$ & $(0.00456)$ & $(0.00403)$ & $(0.00384)$ & $(0.00362)$ & $(0.00262)$ \\
\hline \multirow[t]{2}{*}{$N P I$} & $0.278 * * *$ & $0.101 * * *$ & $0.0672 * * *$ & $0.271 * * *$ & $0.0784 * * *$ & $0.0467 * * *$ \\
\hline & $(0.00690)$ & $(0.00594)$ & $(0.00528)$ & $(0.00542)$ & $(0.00432)$ & $(0.00343)$ \\
\hline \multirow[t]{2}{*}{$N C E$} & $0.109 * * *$ & $0.0821 * * *$ & $0.0477 * * *$ & 0.0738 *** & $0.0589 * * *$ & $0.0268 * * *$ \\
\hline & $(0.00503)$ & $(0.00557)$ & $(0.00515)$ & $(0.00413)$ & $(0.00465)$ & $(0.00336)$ \\
\hline \multirow[t]{2}{*}{$N C I$} & $0.281 * * *$ & $0.125^{* * *}$ & $0.0721 * * *$ & $0.283 * * *$ & $0.177 * * *$ & $0.0739 * * *$ \\
\hline & $(0.00899)$ & $(0.00727)$ & $(0.00665)$ & $(0.00707)$ & $(0.00559)$ & $(0.00432)$ \\
\hline Gözlem Sayısı & 52857 & 52857 & 29830 & 52891 & 52891 & 29860 \\
\hline \multirow[t]{3}{*}{$R^{2}$} & 0.550 & 0.194 & & 0.450 & 0.139 & \\
\hline & & $L P$ & & & TFP & \\
\hline & OLS & $\overline{\mathrm{FE}}$ & $\overline{G M M}$ & OLS & $\overline{F E}$ & $\overline{G M M}$ \\
\hline \multirow[t]{2}{*}{$N P E$} & $0.109 * * *$ & $0.0107 *$ & $0.0226 * * *$ & $0.108 * * *$ & $0.0103 *$ & $0.0189 * * *$ \\
\hline & $(0.00041)$ & $(0.00609)$ & $(0.00766)$ & $(0.00056)$ & $(0.00622)$ & $(0.00635)$ \\
\hline \multirow[t]{2}{*}{$N P I$} & $0.1525 * * *$ & 0.0553 *** & $0.0445^{* * *}$ & $0.1363 * * *$ & $0.0438 * * *$ & $0.0375 * * *$ \\
\hline & $(0.0061)$ & $(0.00793)$ & $(0.01000)$ & $(0.0094)$ & $(0.00812)$ & $(0.00828)$ \\
\hline \multirow[t]{2}{*}{$N C E$} & $0.1478 * * *$ & $0.0315 * * *$ & $0.0418 * * *$ & $0.1434 * * *$ & $0.0500 * * *$ & $0.0409 * * *$ \\
\hline & $(0.0043)$ & $(0.00702)$ & $(0.00972)$ & $(0.0023)$ & $(0.00716)$ & $(0.00802)$ \\
\hline \multirow[t]{2}{*}{$N C I$} & $0.1869 * * *$ & 0.0794 *** & $0.0508 * * *$ & $0.1617 * * *$ & $0.0740 * * *$ & $0.0496 * * *$ \\
\hline & $(0.0079)$ & $(0.00958)$ & $(0.0126)$ & $(0.0101)$ & $(0.00978)$ & $(0.0105)$ \\
\hline \multirow{4}{*}{$\begin{array}{l}\text { Gözlem Sayısı } \\
R^{2}\end{array}$} & 51192 & 51192 & 27938 & 50526 & 50526 & 27820 \\
\hline & 0.2399 & 0.064 & & 0.1956 & 0.026 & \\
\hline & & CAPINT & & & $\overline{W A G E \_L}$ & \\
\hline & OLS & $\mathrm{FE}$ & GMM & OLS & $\mathrm{FE}$ & GMM \\
\hline \multirow[t]{2}{*}{ NPE } & $0.0169 * * *$ & $0.0159 * * *$ & $0.0139 * * *$ & 0.00206 & 0.00193 & 0.00324 \\
\hline & $(0.00565)$ & $(0.00471)$ & $(0.00340)$ & $(0.00364)$ & $(0.00244)$ & $(0.00118)$ \\
\hline \multirow[t]{2}{*}{$N P I$} & $0.0180 * * *$ & $0.0174 * * *$ & $0.0141 * * *$ & $0.0301 * * *$ & $0.0222 * * *$ & $0.0130 * * *$ \\
\hline & $(0.00590)$ & $(0.00695)$ & $(0.00447)$ & $(0.00438)$ & $(0.00333)$ & $(0.00418)$ \\
\hline \multirow[t]{2}{*}{$N C E$} & $0.0184 * * *$ & $0.0161 * *$ & $0.0145^{* * *}$ & $0.0199 * * *$ & $0.0175 * * *$ & $0.0163 * * *$ \\
\hline & $(0.00478)$ & $(0.00677)$ & $(0.00133)$ & $(0.00396)$ & $(0.00396)$ & $(0.00404)$ \\
\hline \multirow[t]{2}{*}{$N C I$} & $0.0194 * *$ & $0.0184 * * *$ & $0.0146 * * *$ & $0.0209 * * *$ & $0.0198 * * *$ & $0.0171 * * *$ \\
\hline & $(0.00921)$ & $(0.00511)$ & $(0.00560)$ & $(0.00509)$ & $(0.00309)$ & $(0.00524)$ \\
\hline Gözlem Sayısı & 52113 & 52113 & 29705 & 52891 & 52891 & 29860 \\
\hline$R^{2}$ & 0.504 & 0.308 & & 0.466 & 0.639 & \\
\hline
\end{tabular}

Not: Tabloda regresyon katsaylları ve parantez içinde yer almış olan sağlam (robust) standart hatalar görülmektedir. Ylldız imleri katsaylların istatistiksel anlamlllı derecelerini göstermektedir (***: $p<1 \%$; **: $p<5 \%$;:p $<10 \%)$. GMM spesifikasyonlarında enstrümanların geçerliliği Sargan testi ile sinanmıştır. Test sonuçları enstrümanların geçerli olduğunu söyleyen HO hipotezini reddetmemektedir. 
Buraya kadar açıklanan bulgular, ithal edilen ara mallarındaki çeşitlenmenin daha çok firma performansı üzerinde ihracattaki çeşitlenmeye göre daha büyük bir etkisi olabileceğine işaret etmektedir. İthalattaki çeşitlenme doğrudan üretimde etkinlik üzerine etki ederken, ihracat çeşitlenmesi daha çok ölçek ekonomileri ile ilişkilidir. Gerçekten de daha yüksek teknolojik içerikli sermaye ve ara mallarının kullanımı, teknolojik gelişme ve dolayısıyla da üretimde etkinlik artışı ile doğrudan ilişkilidir (Damijan ve Kostevc, 2010). Ayrıca, yeni teknolojilere yatırım yapma kararı ithalat yapma kararı ile aynı anda da alınabilir (Damijan vd., 2012). Hem çeşitlenme priminin varlığı ve bu değerin ithalatta belirgin bir şekilde daha yüksek olması sonucu, İtalya imalat sanayi firmaları için Castellani vd. (2010) ve Portekiz imalat sanayi firmaları için Silva vd. (2013) tarafindan da bulunmuştur. Söz konusu çalışmalar ithalata ilişsin bu çeşitlenme primini firmaların yeni ithalat piyasalarına girmek için yüksek sermaye yoğunluklu ithal mallarında içerilmiş yeni bilgiyi değerlendirme, özümseme ve uygulama kabiliyeti ile ilişkilendirmişlerdir.

Çalışmanın bir sonraki aşamasında, çeşitlenme priminin ithalatta neden ihracata göre daha yüksek etkisi olduğuna 1 şık tutulmaktadır. Altomonte ve Békés (2010), ithalatçıların dış ticaret ilişkilerinde ihracatçılara göre daha fazla belirsizlik yaşadıklarını öne sürmektedir (örneğin, ürünün kalitesine ilişkin olarak). Söz konusu belirsizlikler, ticareti yapılan malın karmaşıklığı (complexity-sophistication) arttıkça daha da artacaktır; dolayısıyla, batık maliyetler daha karmaşık mallar için daha yüksek olacaktır. Altomonte ve Békés çalışmalarında, ithalat yapan firmaların ihracat yapanlara göre daha üretken olduğunu göstermekte ve bu durumu, ithal edilen malların daha karmaşık olması ile ilişkilendirmektedir. Ürün çeşitlenmesini ve ürünlerin karmaşıklığını değerlendirmenin bir yolu ürünleri nihai kullanımlarına göre sınıflandırmaktır. $\mathrm{Bu}$ nedenle, çalışmamızda Birleşmiş Milletler'in Geniş Ekonomik Kategoriler (Broad Economic Categories-BEC) Sınıflandırması'nı kullanmakta ve dış ticareti yapılan ürünleri tüketim malları, ara malları ve sermaye malları olmak üzere üç genel kategoriye ayırmaktayız. Sermaye malları (örneğin makineler), diğer kategorilere göre daha karmaşıktır ve satış sonrası hizmet vb. gerektirebilir (Keller \& Yeaple, 2009). Ürün karmaşıklığını kontrol etmek ve çeşitlenme primlerinin halen var olup olmadığını görmek için, firmaları üç grup altında tanımlamaktayız: sermaye malı ticareti yapanlar; ara malı ticareti yapanlar ve tüketim malı ticareti yapanlar. Dış ticaret yapan bir firma için, sermaye malları ticaretinin ${ }^{15}$ payı firmanın toplam ticareti içerisindeki ara ve tüketim mallarının payından daha yüksekse bu firma sermaye malı ticareti yapan bir firma olarak tanımlanmıştır. Diğger kategoriler de benzer şekilde tanımlanmıştır.

15 Bu noktada analizlerimizin tümünün çift taraflı ticaret yapan firmalar için gerçekleştirildiğini hatırlatmakta fayda vardir. Dolaylsiyla firma ticareti firmanin hem ihracat hem de ithalat faaliyetlerini kapsamaktadir. 
Tablo 4'de bahsi geçen firma kategorileri için yapılmış GMM regresyon sonuçları sunulmaktadır. Dikkat edilirse burada sadece firma verimlikleri bir performans göstergesi olarak ele alınmıştır. Öncelikle, her bir grup için bakıldığında, ülke/ürün çeşitlenmesi arttıkça firma verimliliğinin arttığı, diğer bir deyişle çeşitlilik primlerini gösteren katsayıların pozitif ve anlamlı olduğu görülmektedir. İkinci olarak regresyon sonuçları, hem ihracat hem de ithalat bakımından ülke/ürün marjinlerine ilişkin çeşitlenme primlerinde sermaye mallarından tüketim mallarına doğru bir sıralamaya işaret etmektedir. En yüksek çeşitlenme primi sermaye malı ticareti yapan firmalar için gözlenirken en düşük primler ağırlıklı olarak tüketim malı ticareti yapan firmalar için gözlenmektedir. Örneğin, ihracatta pazar çeşitlenmesi ve toplam faktör verimliliği ele alındığında; çeşitlenme primleri sermaye, ara ve tüketim malları için sirasıyla $0.0685,0.0539$ ve 0.0269 'dur. Ülke ve ürün marjinlerindeki çeşitlenme, gerek sermaye gerekse ara malları için ithalatta ihracattan daha büyük çeşitlenme primleri ortaya çıkarır. Öte yandan sonuçlarımız, ağırlıklı olarak tüketim malı ticareti yapan firmalara bakıldığında; çeşitlenme primlerinin ihracatta ithalata göre daha yüksek olduğu farklı bir tablo ortaya koymaktadır.

Tablo: 4

BEC’e Göre Firma Grupları ve Çeşitlenme Primleri (2003-2010)

\begin{tabular}{|c|c|c|c|c|c|c|}
\hline & \multicolumn{3}{|c|}{$\overline{L P}$} & \multicolumn{3}{|c|}{$T F P$} \\
\hline & Sermaye malı & Ara malı & Tüketim malı & Sermaye malı & Ara malı & Tüketim malı \\
\hline \multirow[t]{2}{*}{ NPE } & $0.0239 * * *$ & $0.0157 *$ & $0.0108^{*}$ & $0.0297 * * *$ & $0.0134^{*}$ & 0.0109 \\
\hline & $(0.0021)$ & $(0.00925)$ & $(0.0064)$ & $(0.0019)$ & $(0.00811)$ & $(0.0120)$ \\
\hline \multirow[t]{2}{*}{$N P I$} & $0.0453 * * *$ & $0.0447 * * *$ & $0.0371 * *$ & $0.0383 * * *$ & $0.0373 * * *$ & $0.0360 * *$ \\
\hline & $(0.0029)$ & $(0.0127)$ & $(0.0157)$ & $(0.0025)$ & $(0.0111)$ & $(0.0145)$ \\
\hline \multirow[t]{2}{*}{$N C E$} & $0.0624 * * *$ & $0.0468 * * *$ & $0.0303^{*}$ & $0.0685^{* * *} *$ & $0.0539 * * *$ & $0.0269 *$ \\
\hline & $(0.0182)$ & $(0.0119)$ & $(0.0157)$ & $(0.0160)$ & $(0.0104)$ & $(0.0144)$ \\
\hline \multirow[t]{2}{*}{$N C I$} & $0.0676^{* * * *}$ & $0.0655^{* * *} *$ & $0.0379 *$ & $0.0713 * * *$ & $0.0548^{* *}$ & 0.0209 \\
\hline & $(0.0102)$ & $(0.0158)$ & $(0.0198)$ & $(0.0132)$ & $(0.0139)$ & $(0.0183)$ \\
\hline Gözlem sayısı & 3404 & 15517 & 8893 & 3394 & 15460 & 8844 \\
\hline
\end{tabular}

Not: Tabloda regresyon katsaylları ve parantez içinde yer almış olan sağlam (robust) standart hatalar görülmektedir. Yıldız imleri katsaylların istatistiki anlamlıllk derecelerini göstermektedir $(* * *: p<1 \%$; $* *: p<5 \%$; $\left.{ }^{*}: p<10 \%\right)$. GMM spesifikasyonlarında enstrümanların geçerliliği Sargan testi ile sinanmıştır. Test sonuçları enstrümanların geçerli olduğunu söyleyen HO hipotezini reddetmemektedir.

Ürün karmaşıklığını kontrol edebilmek için BEC sınıflandırmasına alternatif olarak, OECD’nin (2011) teknoloji sınıflandırması da kullanılmıştır. Buna göre firmalar faaliyet gösterdikleri sektörlere göre düşük teknolojili, orta teknolojili ve yüksek teknolojili firmalar olarak sınıflandırılmıştır. Tablo 5'de ilgili firma örneklemlerine ait GMM regresyonları görülmektedir. Örnek büyüklüklerinden hareketle, Türkiye imalat sanayi firmalarının büyük bir kısmının düşük teknolojili olarak sınıflandırılan sektörlerde yoğunlaştığı söylenebilir. Dış ticarette ülke/ürün çeşitlenmesinin firma verimliliği üzerine etkisi, tüm gruplar için pozitif ve istatistiksel olarak anlamlıdır. Bu durum, teknoloji düzeyi 
ne olursa olsun çeşitlenmesi daha fazla olan firmaların daha iyi performans gösterdiğine işaret etmektedir. Önceki bulgularımıza ek olarak, çeşitlenmenin etkisi, yüksek teknolojili olarak tanımlanan sektörlerde faaliyet gösteren firmalarda düşük/orta teknolojili sektörlerde faaliyet gösterenlere göre daha belirgindir. Ayrıca yukarıdaki bulgularımızla paralel biçimde ülke marjinlerindeki çeşitlenme ve ürün marjinlerindeki çeşitlenmeye göre; ithalattaki çeşitlenme ise ihracattaki çeşitlenmeye göre daha etkilidir.

Tablo: 5

OECD Sektör Sınıflamasına Göre Firma Grupları ve Çeşitlenme Primleri

\begin{tabular}{|c|c|c|c|c|c|c|}
\hline & \multicolumn{3}{|c|}{$L P$} & \multicolumn{3}{|c|}{ TFP } \\
\hline & Düşük & Orta & Yüksek & Düşük & Orta & Yüksek \\
\hline & Teknoloji & Teknoloji & Teknoloji & Teknoloji & Teknoloji & Teknoloji \\
\hline \multirow[t]{2}{*}{$N P E$} & 0.00964 & $0.0280 * *$ & $0.0391 * *$ & 0.00985 & $0.0216^{*}$ & $0.0323 * *$ \\
\hline & (0.0104) & $(0.0115)$ & $(0.0161)$ & $(0.00932)$ & $(0.0124)$ & $(0.0131)$ \\
\hline \multirow[t]{2}{*}{$N P I$} & $0.0410 * *$ & $0.0438 * *$ & $0.0501 * *$ & $0.0355 * * *$ & $0.0293 *$ & $0.0548 * * *$ \\
\hline & $(0.0232)$ & $(0.0181)$ & $(0.0217)$ & (0.0108) & $(0.0166)$ & $(0.0176)$ \\
\hline \multirow[t]{2}{*}{$N C E$} & $0.0362 * * *$ & $0.0465 * *$ & $0.0517 * *$ & $0.0293 * *$ & $0.0583 * * *$ & $0.0644 * * *$ \\
\hline & $(0.0127)$ & $(0.0186)$ & $(0.0214)$ & $(0.0113)$ & $(0.0170)$ & $(0.0173)$ \\
\hline \multirow[t]{2}{*}{$N C I$} & $0.0424 * *$ & $0.0474 * *$ & $0.0650 * *$ & $0.0304 * *$ & $0.0606 * *$ & $0.0657 * * *$ \\
\hline & $(0.0168)$ & $(0.0228)$ & $(0.0269)$ & $(0.0151)$ & $(0.0210)$ & $(0.0218)$ \\
\hline Gözlem Sayısı & 13248 & 6677 & 8013 & 13166 & 6665 & 7989 \\
\hline \multicolumn{7}{|c|}{ 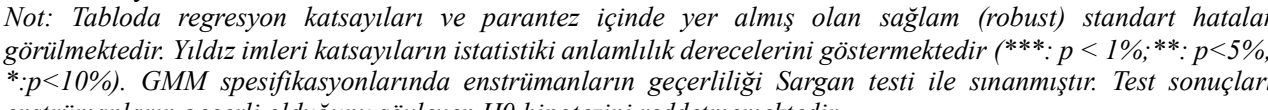 } \\
\hline
\end{tabular}

\section{Sonuç}

$\mathrm{Bu}$ çalışma, firmaların hem ihracat hem de ithalat faaliyetlerini göz önünde bulundurarak; dış ticaretteki ürün ve pazar çeşitlenmesinin firma performansı üzerindeki etkilerine odaklanmaktadır. Çalışma 2003-2010 döneminde, 19+ çalışanı olan tüm Türkiye imalat sanayi firmalarını kapsamaktadır. Çalışmanın sonuçları göre, firmalar uluslararası ticarette gerek ülke gerekse ürün çeşitliliği bakımından ne kadar gelişmişlerse, o kadar büyük, o kadar sermaye yoğun ve o kadar üretken olmaktadırlar. Bununla birlikte diş ticaretteki ülke çeşitlenmesinin ortaya çıkardığı performans primleri ürün çeşitlemesine göre daima daha yüksektir. Öte yandan ithalatta ortaya çıkan ülke/ürün çeşitlenmesi firma performansına ihracat çeşitlenmesine göre daha büyük katkılar sağlamaktadır. Ülke/ürün çeşitlenmesinin getirileri sermaye malı ihraç/ithal eden firmalar için tüketim malı ihraç/ithal eden firmalara göre daha yüksektir. Son olarak çeşitlenmenin etkisi, yüksek teknolojili olarak tanımlanan sektörlerde faaliyet gösteren firmalarda düşük/orta teknolojili sektörlerde faaliyet gösteren firmalara göre daha belirgindir. 


\section{Kaynakça}

Altomonte, C. \& G. Bekes (2010), "Trade Complexity and Productivity", CeFiG Working Papers, 12, Center for Firms in the Global Economy.

Andersson, M. \& S. Johansson \& H. Lööf (2008), "Productivity and International Trade: Firm Level Evidence from a Small Open Economy", Review of World Economics, 144(4), 774-801.

Arkolakis, C. \& M.A. Muendler (2010), "The Extensive Margin of Exporting Products: A Firm-level Analysis.” NBER Discussion Paper, 16641, National Bureau of Economic Research, Cambridge, Mass.

Arellano, M. \& S. Bond (1991), "Some Tests of Specification for Panel Data: Monte Carlo Evidence and an Application to Employment Equations", Review of Economic Studies, 58(2), 277 297.

Bernard, A.B. \& J. Eaton \& J.B. Jensen \& S.S. Kortum (2003), "Plants and Productivity in International Trade", American Economic Review, 93, 1268-90.

Bernard, A.B. \& J.B. Jensen (2004), "Why Some Firms Export", Review of Economics and Statistics, 86, 561-569.

Bernard, A.B. \& J.B. Jensen \& S. Redding \& P. Schott (2007), "Firms in International Trade", Journal of Economic Perspectives, 21(3), 105-30.

Bernard, A.B. \& J.B. Jensen \& S. Redding \& P. Schott (2009), "The Margins of US Trade (Long Version)", NBER Discussion Paper, 14662, National Bureau of Economic Research, Cambridge, Mass.

Bernard, A.B. \& J.B. Jensen \& S. Redding \& P. Schott (2010), "Multiple-product Firms and Product Switching", American Economic Review, 100(1), 70-97.

Blundell, R. \& S. Bond (1998), "Initial Conditions and Moment Restrictions in Dynamic Panel Data Models", Journal of Econometrics, 87(1), 115-143.

Bond, S. (2002), "Dynamic Panel Data Models: A Guide to Micro Data Methods and Practice", Working Paper 09/02, Institute for Fiscal Studies, London.

Cadot, O. \& C. Carrere \& V.S. Kahn (2011), "Export Diversification: What's behind the Hump?", Review of Economics and Statistics, 93, 590-605.

Castellani, D. \& F. Serti \& C. Tomasi (2010), "Firms in International Trade: Importers' and Exporters' Heterogeneity in Italian Manufacturing Industry", The World Economy, 33(3), 424-457.

Damijan, J.P. \& J. Konings \& S. Polanec (2013), "Pass-on trade: why do firms simultaneously engage in two-way trade in the same varieties?", Review of World Economics, 149(1), 85-111.

Damijan J.P. \& A. Kostevc (2010), "Learning from trade through innovation: Causal link between imports, exports and innovation in Spanish microdata", LICOS Discussion Papers 26410, LICOS - Centre for Institutions and Economic Performance, KU Leuven.

Damijan, J.P. \& S. Polanec \& J. Prasniak (2004), "Self-selection, Export Market Heterogeneity and Productivity Improvements: Firm Level Evidence from Slovenia", LICOS Discussion Paper 148/2004, LICOS Centre for Transition Economics. 
Eaton J. \& S.S. Kortum \& F. Kramarz (2004), "Dissecting trade: firms, industries, and export destinations", American Economic Review, 94, 150-54.

Hall, B.H. \& J. Mairesse (1995), "Exploring the Relationship between R\&D and Productivity in French Manufacturing Firms", Journal of Econometrics, 65, 263-293.

Imbs, J. \& R. Wacziarg (2003), “Stages of Diversification”, American Economic Review, 1993, 6386.

Keller, W. \& S.R. Yeaple (2009), "Global Production and Trade in the Knowledge Economy," CEPR Discussion Papers 7175, C.E.P.R. Discussion Papers.

Levinsohn, J. \& A. Petrin (2003), "Estimating Production Functions Using In- puts to Control for Unobservables." The Review of Economic Studies, 70(2), 317-341.

Mayer, M. \& G. Ottaviano (2007), "The Happy Few: The Internationalisation of European Firms. New Facts Based on Firm-level Evidence", Blueprint Series, 12, Brugel.

Mayer, T. \& M. Melitz \& G. Ottaviano (2011), "Market Size, Competition, and the Product Mix of Exporters", NBER Discussion Paper, 16959, National Bureau of Economic Research, Cambridge, Mass.

Melitz, M.J. (2003), “The Impact of Trade on Intra-Industry Reallocations and Aggregate Industry Productivity", Econometrica, 71(6), 1695-1725.

Michaely, M. (1958), "Concentration of Exports and Imports: An International Comparison”, The Economic Journal, Vol. 68, No. 272, 722-736.

Muuls, M. \& M. Pisu (2009), "Imports and Exports at the Level of the Firm: Evidence from Belgium”, The World Economy, 32(5), 692-734.

Parteka, A. \& M. Tamberi (2011), "Determinants of Export Diversification: An Empirical Investigation", mimeo, Universita Politecnica delle, Marche.

Silva, A. \& O. Afonso \& A.P. Africano (2013), "Economic Performance and International Trade Engagement: The Case of Portuguese Manufacturing Firms", International Economics and Economic Policy, 10, 521-547. 
Dalgıç, B. \& B. Fazlıŏlu (2015), "Dış Ticarette Ürün/Ülke Çeşitliliği ve Firma Performans1: Türkiye Örneği”, Sosyoekonomi, Vol. 23(26), 7-23. 